\title{
Development of the Interdisciplinary Evidence-Based S3 Guideline for the Diagnosis and Treatment of Prostate Cancer: Methodological Challenges and Solutions
}

\author{
Christoph Rölliga,b Monika Nothacker ${ }^{\mathrm{a}} \quad$ Achim Wöckel $^{\mathrm{c}} \quad$ Susanne Weinbrenner $^{\mathrm{a}}$ \\ Manfred Wirth $^{d}$ Ina Kopp ${ }^{\mathrm{e}}$ Günter Ollenschläger ${ }^{\mathrm{a}}$ Lothar Weißbach $^{f}$ \\ ä̈rztliches Zentrum für Qualität in der Medizin (ÄZQ), Berlin, \\ ${ }^{b}$ Medizinische Klinik und Poliklinik I, Universitätsklinikum der TU Dresden, \\ 'Klinik für Frauenheilkunde und Geburtshilfe, Universitätsklinikum UIm, \\ ${ }^{d}$ Klinik und Poliklinik für Urologie, Universitätsklinikum der TU Dresden, \\ ${ }^{\text {e}}$ Arbeitsgemeinschaft der Wissenschaftlich-Medizinischen Fachgesellschaften, Düsseldorf, \\ 'Stiftung Männergesundheit, Berlin, Germany
}

Key Words

Clinical guideline - Evidence-based medicine .

Consensus - Prostate cancer: Treatment, Diagnosis,

Rehabilitation

\section{Summary}

Evidence-based guidelines are important sources of knowledge in everyday clinical practice. In 2005, the German Society for Urology decided to develop a highquality evidence-based guideline for the early detection, diagnosis and treatment of the different clinical manifestations of prostate cancer. The guideline project started in 2005 and involved 75 experts from 10 different medical societies or medical organizations including a patient organization. The guideline was issued in September 2009 and consists of 8 chapters, 170 recommendations, and 42 statements. Due to the broad spectrum of clinical questions covered by the guideline and the high number of participating organizations and authors, the organizers faced several methodological and organizational challenges. This article describes the methods used in the development of the guideline and highlights critical points and challenges in the development process. Strategies to overcome these problems are suggested which might be beneficial in the development of new evidencebased guidelines in the future.
Schlüsselwörter

Klinische Leitlinie - Evidenzbasierte Medizin .

Konsensbildung · Prostatakarzinom: Therapie, Diagnostik, Rehabilitation

\section{Zusammenfassung}

Evidenzbasierte Leitlinien sind wichtige Quellen komprimierten Wissens für die tägliche klinische Praxis. Die Deutsche Gesellschaft für Urologie beschloss im Jahr 2005, eine qualitativ hochwertige evidenzbasierte Leitlinie zur Früherkennung, Diagnose und Behandlung der verschiedenen klinischen Manifestationen des Prostatakarzinoms zu erstellen. Das Leitlinienprojekt begann im Jahr 2005 unter Mitwirkung von 75 Experten und Patientenvertretern aus 10 verschiedenen Fachgesellschaften und Organisationen. Die Leitlinie wurde im September 2009 veröffentlicht und besteht aus 8 Kapiteln mit insgesamt 170 Empfehlungen und 42 Statements. Das breite thematische Spektrum der Leitlinie und die hohe Zahl teilnehmender Autoren und Organisationen stellten die Organisatoren vor verschiedene methodische und logistische Herausforderungen. Dieser Beitrag stellt die angewendete Methodik bei der Leitlinienerstellung dar und betont kritische Punkte und Probleme der Erstellung. Die beschriebenen Lösungsansätze können bei der Planung und Durchführung künftiger evidenzbasierter Leitlinienprojekte hilfreich sein.

\section{KARGER}

Fax +497614520714

Information@Karger.de

www.karger.com (c) 2010 S. Karger GmbH, Freiburg

www.karger.com/onk 


\section{Introduction}

Clinical guidelines play a growing role in clinical practice and in the setting of therapeutic standards. Clinical guidelines are popular among German urologists, who value their clinical advice and use guideline recommendations in everyday practice, as recently shown by a large survey on guideline use amongst German urologists. The results of the survey suggest that up-to-date evidence and clear recommendations are crucial points for acceptance amongst users and for successful implementation [1]. Except for the S3 guideline for Early Detection of Prostate Cancer published in 2002, so far all other German guidelines in urology were exclusively based on either expert consensus or evidence (level S1/S2) but did not meet high-quality requirements, i.e. evidence plus formal techniques of consensus (S3 level). Due to the high incidence and prevalence of prostate cancer in Germany with 58,000 newly diagnosed cases per year [2], there is a considerable need for diagnostic and therapeutic standards. Therefore, the German Society of Urology (DGU) decided to develop a high-quality S3 guideline for early detection, diagnosis and treatment of the different clinical manifestations of prostate cancer. A steering committee was formed in 2004 and funding was obtained from the Deutsche Krebshilfe e.V. (DKH, German Cancer Aid).

\section{Organization, Responsibilities and Time Lines}

The steering committee consisted of 5 urologists nominated by the DGU, 4 radiooncologists nominated by the German Society for Radio-Oncology (DEGRO) and 1 medical oncologist representing the German Society for Haematology and Oncology (DGHO). In order to ensure expertise in special issues of prostate cancer management and to pursue an interdisciplinary approach, the steering committee invited other scientific societies involved in the management of prostate cancer and patient organizations to participate in the guideline development process. The Association of the Scientific Medical Societies in Germany (AWMF) and the Deutsche Krebsgesellschaft (DKG, German Cancer Society) supervised the development. In 2006, the Ärztliches Zentrum für Qualität in der Medizin (ÄZQ, Agency for Quality in Health Care) was commissioned for methodical and scientific input and project management. The organizational structure of the guideline project is shown in figure 1 .

In order to guarantee a structured development process, the different aspects of prostate cancer treatment were summarized under 5 main themes: prevention and early detection, diagnosis and staging, treatment of localized prostate cancer, treatment of advanced prostate cancer, rehabilitation, supportive care, psychooncology, and quality of life.

The 5 themes were subdivided into 42 key questions dealing with clinical issues of high priority to the guideline group. Priorities were set within the steering committee and discussed both with methodology experts from the ÄZQ and the AWMF and also with guideline authors during the consensus conferences. Working groups were formed for each key question consisting of 2-8 clinical experts and/or patient representatives. Authors for working groups were selected by their scientific medical society. The composition of working groups was defined by the steering committee and depended on the specific key question. While there was a higher quota of urologists in working groups on surgical topics such as prostatectomy, lymphadenectomy or biopsy, working groups on radiotherapy were formed by a higher percentage of radiooncologists. In general, the majority of experts in the guideline working groups were urologists $(66 \%)$, followed by radiooncologists $(17 \%)$, representatives of other specialties and patient representatives. The main reasons for this distribution were the leading role of the DGU in the guideline development process and the fact that, in Germany, most patients with prostate cancer are diagnosed by urologists.
Fig. 1. Organization and responsibilities in the guideline project. The following organizations were involved: Deutsche Gesellschaft für Urologie (DGU), Berufsverband Deutscher Urologen (BDU), Deutsche Gesellschaft für Radioonkologie (DEGRO), Berufsverband der Deutschen Strahlentherapeuten (BVDST), Deutsche Gesellschaft für Hämatologie und Onkologie (DGHO), Deutsche Röntgengesellschaft (DRG), Deutsche Gesellschaft für Pathologie (DGP), Deutsche Gesellschaft für Nuklearmedizin (DGN), Bundesverband Prostatakrebs-Selbsthilfe (BPS), Deutsche Krebsgesellschaft (DKG), Ärztliches Zentrum für Qualität in der Medizin (ÄZQ), Arbeitsgemeinschaft der Wissenschaftlichen Medizinischen Fachgesellschaften (AWMF).

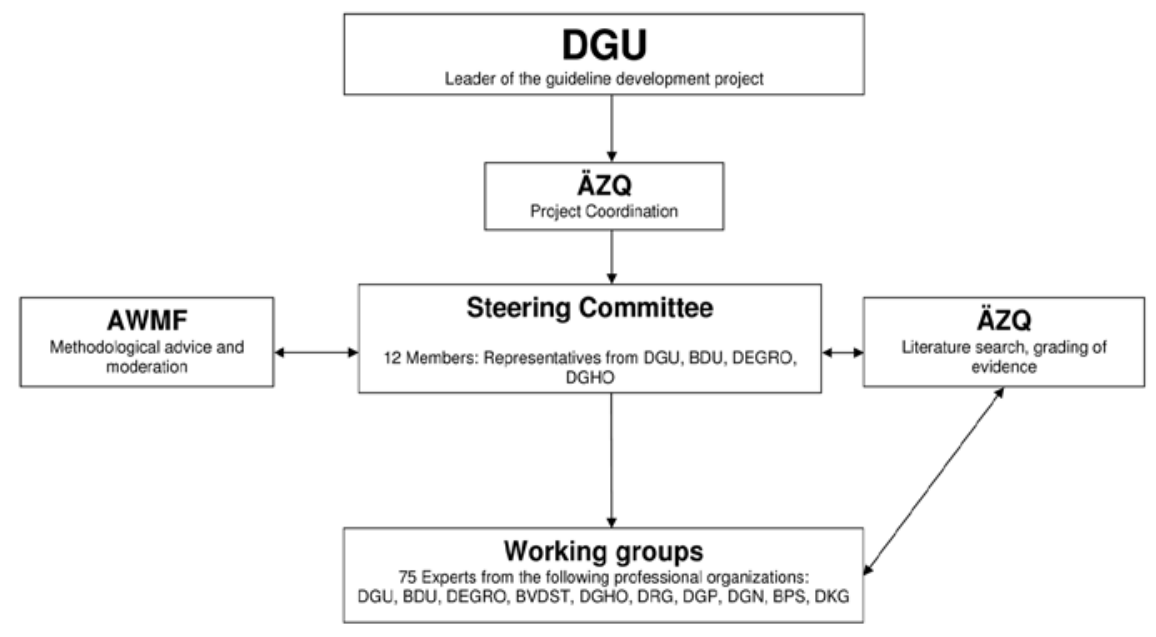


The first meeting of the guideline group took place in 2005 , followed by 5 consensus conferences between September 2007 and June 2009.

\section{Identification of Evidence and Formulation of Recommendations}

A systematic literature search was performed for each key question. Both evidence-based guidelines and primary evidence were used for the development of recommendations. The search for international reference guidelines was performed using the database of the Guidelines International Network (G-I-N), the Guideline Finder of the British National Health Service, the National Guidelines Clearinghouse (NGC), the PubMed tool of the National Library of Medicine, and the German database of the AWMF. After appraisal of the methodological quality, the guidelines of the following organizations were selected as reference: (i) American Urological Association (AUA) (2005) [3], (ii) European Association of Urology (EAU, 2007/2009) [4, 5], (iii) National Institute for Health and Clinical Excellence (NICE, 2008) [6], and (iv) the Dutch Guideline Platform (EBRO, 2007) [7]. The Cochrane Library and PubMed were searched for systematic reviews; PubMed was used as a resource for primary literature. In general, only recent evidence of the last 5 years was selected. All search results were made accessible for the participating experts via an internet tool. The results of the selected publications were extracted and displayed in evidence tables. The level of evidence of each publication was classified using the classification of the Scottish Intercollegiate Guidelines Network (SIGN) [8]. Based on the evidence tables, the body of evidence was summarized and suggestions for guideline recommendations were made by members of the working groups and evidence-based medicine (EBM) experts from the ÄZQ. Upon completion, the draft chapters were sent electronically to the clinical experts and discussed between clinical and EBM experts in telephone meetings. Depending on the complexity of the topic, one or two telephone meetings were necessary for each chapter.

\section{Reaching Consensus and Grading Recommendations}

All recommendations had to pass a two-step consensus process consisting of (i) a Nominal Group Process (NGP) [9] in groups of 20-25 clinical experts under supervision and guidance of EBM specialists and (ii) general voting of all guideline authors. All experts met in consensus conferences, discussing the chapters via NGP and voting for final recommendations. Additionally to the wording of the recommendations, the strength of recommendation was determined in the consensus process. Only recommendations with an acceptance rate of $>75 \%$ were included in the guideline. EBM experts had only advising responsibility and did not take part in the voting process. The development process of guideline recommendations is depicted in figure 2.

\section{Public Consultation and Final Editing}

Following the last consensus conference, all guideline chapters were published online for public comments for 4 weeks. Public comments were discussed and necessary changes were made by the steering committee. The final version of the guideline was presented at the annual meeting of the German Society of Urology (DGU) in September 2009 [10].

\section{Results}

A total of 75 clinical experts and patient representatives from 10 organizations and groups and 4 EBM specialists were involved in the development of the guideline. 6 conferences were held, each taking 1-2 days. As a result of 56 separate literature searches, 12,189 hits were screened and 420 publications were included as a source of evidence. Based on $42 \mathrm{key}$

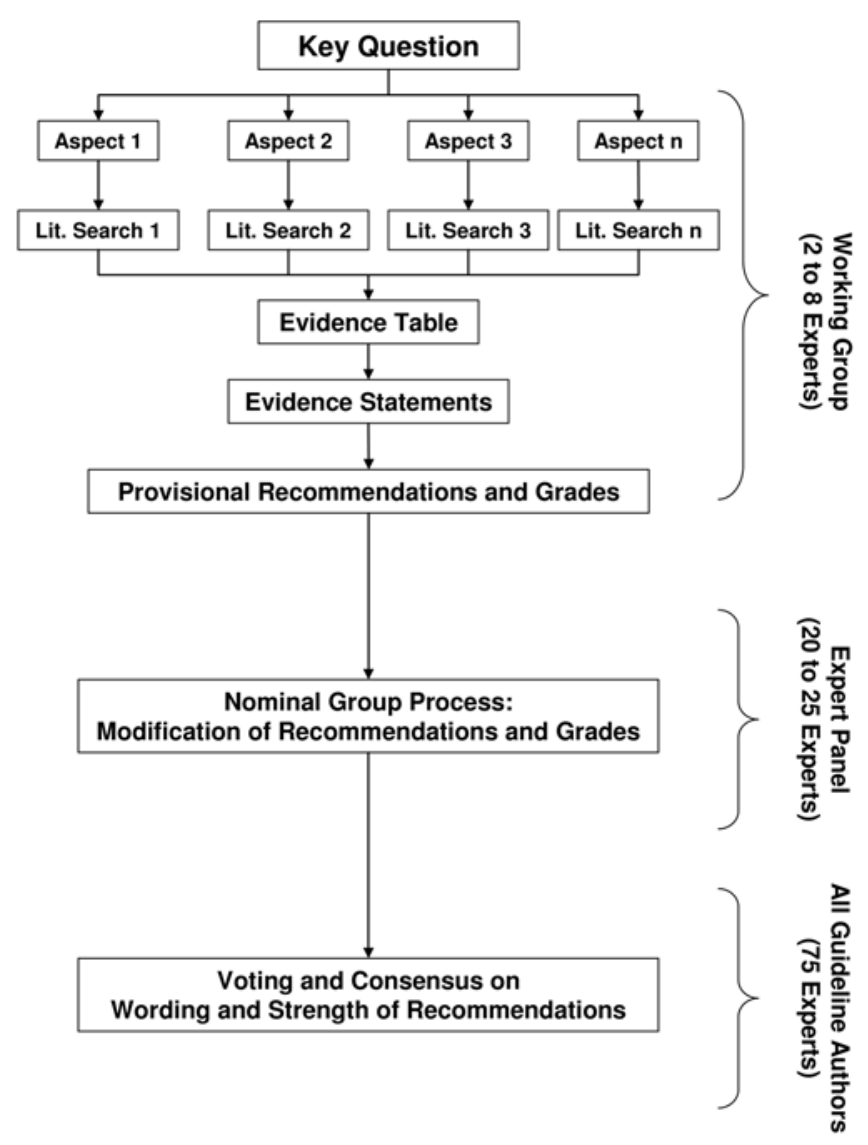

Fig. 2. Development of final guideline recommendations. Every step of the development process was coordinated and supervised by EBM experts from the $\ddot{A} Z Q$. 
Table 1. Chapter headings of the guideline

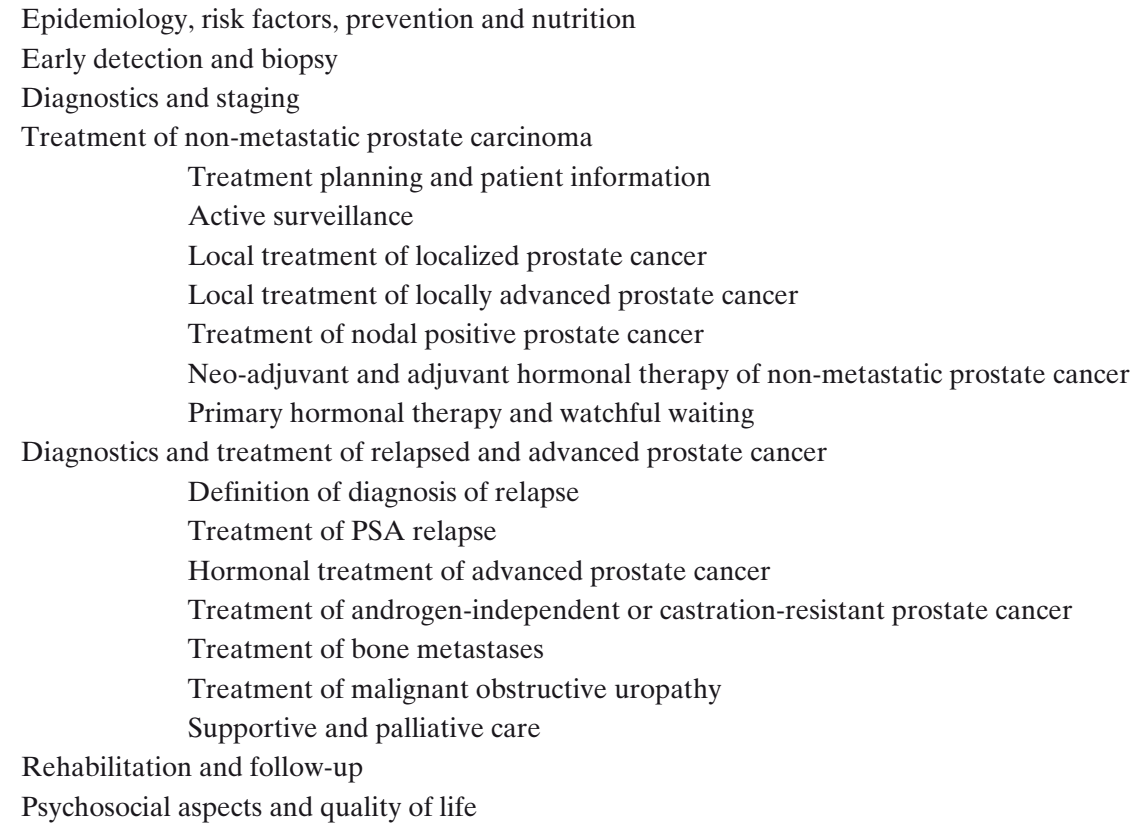

questions, 8 chapters were formed, containing 170 recommendations and 42 statements. The chapter headings are shown in table 1 . The majority of recommendations $(64 \%)$ were graded as strong recommendations (grade $\mathrm{A}, \mathrm{n}=109$ ). $1 / 5$ of the recommendations $(21 \%)$ were assigned a weak recommendation (grade $\mathrm{B}, \mathrm{n}=36$ ) and $15 \%$ of the recommendations were labeled as open or optional (grade $0, \mathrm{n}=25$ ). 23 comments were received during the public consultation period, leading to 5 adjustments of recommendations.

\section{Challenges, Problems and Solutions}

Due to the large number of people involved in the project, sufficient and constructive communication between experts and patients located in different regions of Germany, Austria and Switzerland formed the biggest challenge for the project management. Different approaches to certain clinical problems between varying numbers of experts of various specialties aggravated possible communication problems. For example, the value and significance of magnetic resonance imaging (MRI) and transrectal ultrasound in primary diagnosis and staging of localized prostate cancer was a highly controversial topic. 2 approaches were successfully used in order to facilitate communication. Firstly, the process of conducting the literature search and selection was made transparent using an internet site with a professional literature database ('refshare'). The participating experts were able to reproduce the literature search online, access the selected abstracts and full texts and add important publications not yielded by the search strategy. Of even greater importance was the provision of draft chapters including suggestions for recommendations and their discussion in telephone conferences. Both the organization of telephone conferences and creation of draft chapters were done by EBM experts at the ÄZQ, solving both the problem of shortness of expert time and evidence grading. The telephone conferences proved to be an ideal tool for discussing draft chapters and the available evidence and allowed clinicians to accommodate the guideline development in their tight clinical schedule. In order to improve the knowledge of clinicians in EBM methods, training courses were organized including lectures in basics of EBM and grading exercises. The attendance of these courses was mandatory for all authors.

An electronic newsletter was used to update and motivate authors and create a sense of ownership and of commitment to the project.

In the process of guideline development, it became obvious that evidence was lacking for a considerable number of key questions, so-called evidence gaps. Where evidence was lacking, high-quality source guidelines were used as a starting point for a structured expert consensus. Apart from gaps in available evidence, there was also a significant number of topics not covered by the initial project plan. Some topics regarded as essential by the steering committee were then added to the original plan while others were deferred for the future guideline update. In order to account for the quick turnover of medical knowledge, the steering committee decided to subject the guideline to a short-term update process following the concept of a so called 'living guideline'. This will include a structured literature search of selected topics as well as the addition of up to 12 new aspects not covered by the current guideline. Within an annual formal consensus process, recommendations may be changed and new recommendations 
may be approved if necessary. The process will be based on existing organizational structures such as the steering committee and authors from the guideline group. Members of preexisting author groups will cover the 12 new topics. The internet tool will be used for additions and provision of new literature.

\section{Conclusions and Implications for Future Guideline Projects}

The development of a comprehensive evidence-based guideline (S3 level) takes up a considerable amount of time and financial resources and requires efficient project management. In the initial planning phase of a new S3 guideline project, it is essential

- to prioritize topics of interest and to be selective in the choice of topics,

- to balance the desire to involve as many experts as possible with the logistics of coordinating large groups - we feel that the development process becomes very complex if more than 35 experts are involved and if there are large inequalities in numbers of experts of different specialties,
- to seek expert advice in EBM methodology and to consider professional project management,

- to use systematic reviews and international high-quality guidelines as a source of information in order to avoid time consuming and costly literature searches in primary publications,

- to provide opportunities for verbal exchange and discussions between clinical experts and possibly EBM experts in telephone conferences and meetings,

- to actively seek, reveal and describe evidence gaps or important issues not covered by the guideline in order to set aims for future updates and additions.

While the primary development of an evidence-based guideline is a very complex and time-consuming project, its update can rely on the existing guideline structure and should therefore require less resources. A mode of continuous update should be planned as soon as the first edition of the guideline is close to completion.

\section{Conflict of Interest}

The authors declare no conflicts of interest in the work presented here.

\section{References}

1 Busch J, Rollig C, Weissbach L, Kempkensteffen C, Hinz S, Jahnke C, Schostak M, Lein M, Weiker S, Stephan C, Deger S, Ollenschlager G, Miller K, Schrader M: [What is most important is what comes across: Urological guidelines from the target group's point of view]. Urologe A 2010;49:75-80.

2 Robert Koch-Institut (RKI), Gesellschaft der epidemiologischen Krebsregister in Deutschland (GEKID): Krebs in Deutschland 2003-2004. Häufigkeiten und Trends. RKI 2008;6.

3 Thompson I, Thrasher JB, Aus G, Burnett AL, Canby-Hagino ED, Cookson MS, D'Amico AV Dmochowski RR, Eton DT, Forman JD, Goldenberg SL, Hernandez J, Higano CS, Kraus SR, Moul JW, Tangen CM: Guideline for the management of clinically localized prostate cancer: 2007 update. J Urol 2007;177:2106-2131.
4 Heidenreich A, Aus G, Bolla M, Joniau S, Matveev VB, Schmid HP, Zattoni F: EAU guidelines on prostate cancer. Eur Urol 2008;53:68-80.

5 Heidenreich A, Aus G, Bolla M, Joniau S, Matveev VB, Schmid HP, Zattoni F: [EAU guidelines on prostate cancer]. Actas Urol Esp 2009;33:113-126.

6 Graham J, Baker M, Macbeth F, Titshall V: Diagnosis and treatment of prostate cancer: summary of NICE guidance. BMJ 2008;336:610-612.

7 de Reijke TM, Battermann JJ, van Moorselaar RJ, de Jong IJ, Visser AP, Burgers JS: [Practice guideline 'Prostate cancer: diagnosis and treatment']. Ned Tijdschr Geneeskd 2008;152:1771-1775.

8 Harbour R, Miller J: A new system for grading recommendations in evidence based guidelines. BMJ 2001;323:334-336.
9 Arbeitsgemeinschaft der Wissenschaftlichen Medizinischen Fachgesellschaften, Ärztliche Zentralstelle Qualitätssicherung: Das Leitlinien-Manual von AWMF und ÄZQ. Entwicklung und Implementierung von Leitlinien in der Medizin. Z Ärztl Fortbild Qualitätssich 2001;95:4-84.

10 Wirth M, Weissbach L, Ackermann R, Alberti W, Albrecht C, Göckel-Beining B, Fröhner M, Hinkelbein W, Miller K, Rübben H, Wiegel T, Wolff J, Wörmann B: Interdisziplinäre Leitlinie der Qualität S3 zur Früherkennung, Diagnose und Therapie der verschiedenen Stadien des Prostatakarzinoms. Deutsche Gesellschaft für Urologie 2009, www.aezq.de/edocs/pdf/info/s3-leitlinie-prostatakarzinom. 